\title{
Case Study of building Storage Strategy in the Logistics Distribution Center-Logistics Company A as an Example
}

\author{
Ching-Kuei Kao, Guo-Xia Xu, Xiao-Er Fang, and Mei-Chun Zheng
}

\begin{abstract}
Storage and maintenance are essential in warehouse operation management. Accordingly, this study takes a logistics distribution center as the case. In this case, Logistics Company $A$ and $X$ Beverage Company establish a logistics partnership in the supply chain. Logistics Company A is responsible for designing and handling $X$ Beverage Company's cargo storage, transportation, and distribution businesses in big and small retail shops in $Y$ region. Reducing the goods overstock, stock, and stock-out rate and improving the goods' freshness are important because beverages are classified as fast-moving consumer goods. This study develops the storage strategy for goods in X Beverage Company through classified management of goods by activity-based classification (ABC) with the primary aim of increasing the efficiency of storage management. Second, goods stock and management strategies are developed with the aid of EIQ (entry, item, and quantity) analysis and in accordance with results of the $\mathrm{ABC}$ classification. Finally, the EOQ (economic ordering quantity) stock control model is established for large retailers and small retail stores.
\end{abstract}

Index Terms-ABC Classification; EIQ Analysis; EOQ Model; Fast-Moving Consumer Goods; Logistics Distribution Center.

\section{INTRODUCTION}

Warehouse storage is an essential step in the logistics process, which directly reflects the goods' status before and in circulation and serves as the basis for the company in evaluating the goods' production and sales. This step aims to satisfy customer's needs for the goods. Information feedback of warehouse storage management directly influences the company's economy in the management process of warehouse storage operation. For example: through these feedback information, the process optimization of goods entry and out of the warehouse can be development to improve production efficiency, or the reasonable layout of storage site can be planned to reach the acceleration in the turnover rate, or an effective inventory control model can be established to reduce inventory costs and stock out rates. Therefore, the capability of a company to properly handle warehouse storage management is indirectly related to the company's economy [1]-[3].

Published on April 24, 2018.

C. K. Kao is with Department of Logistics Management, Beijing Institute of Technology, Zhuhai (e-mail: ckkao_zhbit@163.com).

G. X. Xu is a college student with Department of Logistics Management, Beijing Institute of Technology, Zhuhai.

X. E. Fang is a college student with Department of Logistics Management, Beijing Institute of Technology, Zhuhai.

M. C. Zheng is a college student with Department of Logistics Management, Beijing Institute of Technology, Zhuhai.
Warehouse storage is a system jointly composed of and coordinated by every process and operation unit. The entire warehouse storage system involves goods purchase and warehousing, warehouse storage and maintenance, and goods to be out of warehouse and sent, three of which jointly connect with one another to fulfill all the functions of warehouse storage [4]-[6]. Goods purchase and warehousing are the first steps of warehouse storage and serve as the premise for conducting goods storage and maintenance. The sending of goods out of the warehouse is the end and completion step of warehouse storage and achieves the aim of storage to maintain the value in use, connect the supply and demand process, and fulfill the transportation of goods along with time shifts. Generally speaking, goods purchase and warehousing, and goods to be out of warehouse and sent require a relatively short time, whereas storage and maintenance require a long time. Therefore, goods storage and maintenance in the warehouse are essential in warehouse operation management [7]. Warehouse goods storage and maintenance refers to the handling, placement, and reasonable and effective planning and management of the goods concerning the storage position after the goods enter the warehouse. The development of the warehousing industry has changed the emphasis of warehouse functions from goods maintenance to goods circulation. Therefore, purchase, storage, and shipping are crucial processes that impose considerable requirements on controlling goods circulation. Sound storage strategies and patterns can effectively reduce warehousing distance and operation time, safeguard quality, and fully utilize storage space.

This study considers a logistics company as the case. This company plans to establish a large regional distribution center (RDC) as the hub of its logistics operation platform to improve the firm's service capability. Integration of RDCs can reduce transportation costs and stock out losses, increase punctuality of deliveries, and enhance the time efficiency of logistics services. The logistics distribution center is equipped with modernized service functions concerning logistics in goods storage, stock and management, transportation, distribution, circulation, and processing. Moreover, it provides a series of services, such as ecommerce, information processing, and information releasing, to become the comprehensive service platform integrated with commerce, logistics, information, and capital. Thus, this study analyzes and develops the storage strategies in the enterprise's logistics distribution center to provide qualified and efficient logistics services for its customers and thus satisfy their needs from this logistics center. 


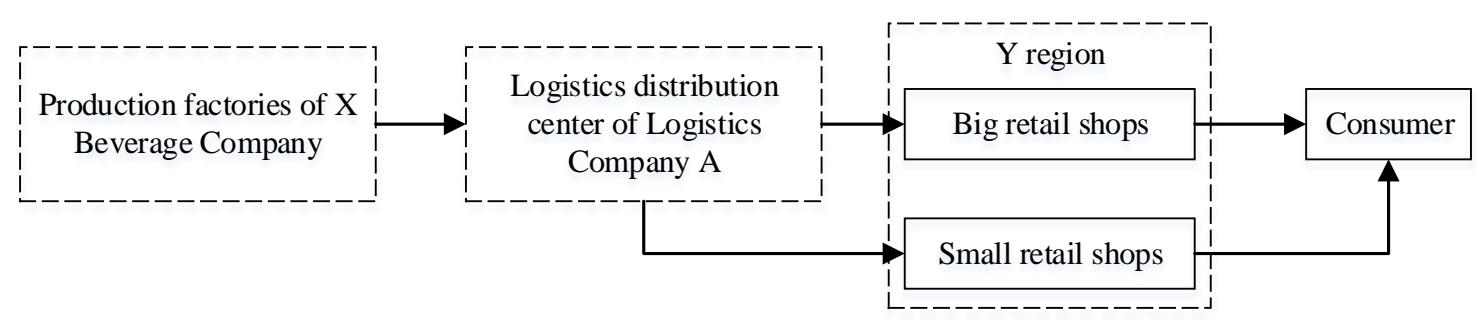

Fig. 1. Supply chain model of X Beverage Company and Logistics Company A

\section{BRIEF INTRODUCTION OF THE COMPANY}

In this case, the logistics distribution center of Logistics Company A applies the modernized system for managing logistics information and builds the perfect system for warehouse storage and distribution. The operation area in the logistics distribution center is divided into the warehouse-in, pallet storage, sorting, equipment storage, warehouse-out, and office areas. Logistics Company A and $\mathrm{X}$ Beverage Company establish a logistics partnership in the supply chain. Logistics Company A designs and handles X Beverage Company's cargo storage, transportation, and distribution businesses in big and small retail shops in $\mathrm{Y}$ region. Fig. 1 presents the supply model of Logistics Company A and X Beverage Company.

$\mathrm{X}$ Beverage Company requires the logistics distribution center of Logistics Company A to be capable of providing distribution services for the retailers and customers, reducing goods overstock, stock, and stock-out rate, and improving the goods' freshness to gain competitive advantage. To establish a mutually beneficial cooperative relationship, X Beverage Company historically provides certain operation data for the logistics distribution center of Logistics Company A for research and aims to produce a scientific and rational storage plan on the basis of such data.

\section{DEVELOPMENT OF STORAGE STRATEGY FOR LOGISTICS DISTRIBUTION CENTER}

First, classified management of goods by activity-based classification $(\mathrm{ABC})$ is developed concerning the storage strategy for goods in the logistics distribution center of Logistics Company A to increase the efficiency of storage management. Second, goods stock and management strategies are developed with the aid of EIQ (entry, item, and quantity) analysis and in accordance with results of the ABC classification. Finally, a storage control model is established for large and small retailers.

\section{A. ABC Classification}

$\mathrm{ABC}$ is commonly adopted in stock management [8], [9], whose main purpose is to achieve proficiency in A-class material for key management to reduce the stock and raise management performance. Considering the differences in demanding quantity and capital of different products in $\mathrm{X}$ Beverage Company, the logistics distribution center of Logistics Company A must handles the products via $\mathrm{ABC}$ classification. Two kinds of sorting shelves are adopted with varying sorting efficiencies in different shelves, especially for the sorting area in the inner logistics center. Differentiated management of goods in the sorting area is considered in the initial construction period of the logistics center.

The order quantity of large retailers in $\mathrm{Y}$ region for $\mathrm{X}$ Beverage Company is stable. Orders from small retailers differ from those from large retailers in that many fragmented goods shall be selected, thereby potentially causing complications in handling. Although the ordered goods' types and quantities of large and small retailers differ, the overall order quantity is stable. This study focuses only on the ordered information of certain small retailers in $\mathrm{Y}$ region for $\mathrm{ABC}$ classification due to the large quantities of commercial data.

ABC classification divides the goods into three types according to the accumulated item percentage and accumulated percentage of the average capital occupation.

(1) Class A: Top goods with the accumulated item percentage of $20 \%$; accumulated percentage of average capital occupation of $75 \%$.

(2) Class B: Goods with accumulated item percentage from $20 \%$ to $50 \%$ and accumulated percentage of average capital occupation from $75 \%$ to $90 \%$.

(3) Class C: Goods that do not fall in Classes A and B.

Class A goods refer to those with few types and in small quantities but with substantial value. Class $C$ goods refer to those with numerous types and large quantities but have small value. Class B goods are those between Classes A and C.

According to Table I, Class A, B, and C beverages come in 11,16 , and 27 types, respectively, as determined in the ABC classification; the accumulated capital percentages of the daily mean sales volumes of these beverages are $75.02 \%, 15.04 \%$, and $9.94 \%$, respectively. According to the accumulated item percentage and accumulated percentage of capital occupation in Table $I$, the graph of $A B C$ classification is shown in Fig. 2.

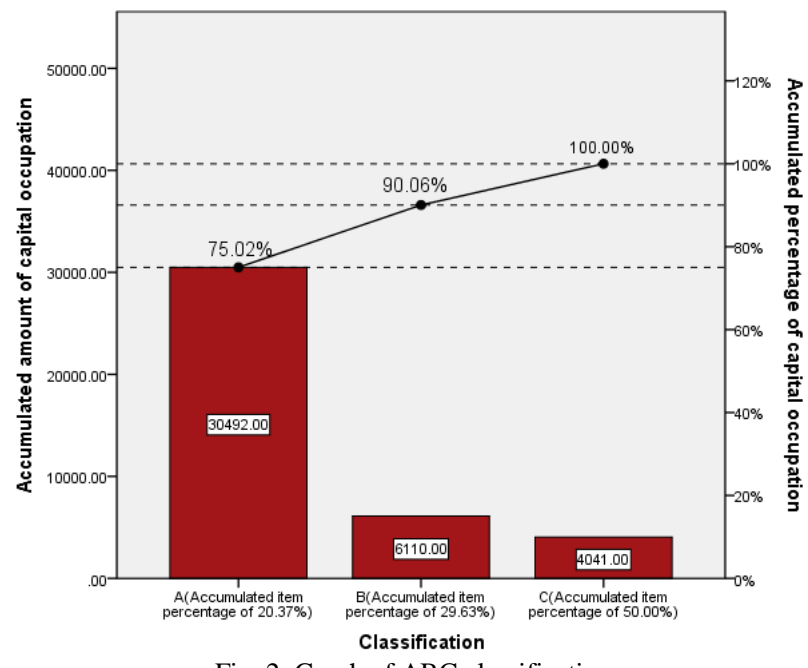

Fig. 2. Graph of ABC classification 


\section{B. Storage Management Strategies}

Storage management strategies include two parts. First, the storage position is arranged for the goods provided to the small retailers. Second, the goods sorting strategy is designed.

\section{1) Storage Position Arrangement}

The pallet storage area in the logistics distribution center of Logistics Company A has two types of shelves, namely, stereoscopic warehouse and common pallet shelves, which are mainly the storage areas for commodities and goods, respectively. The storage position for the goods provided for small retailers shall be arranged in accordance with the results of the $\mathrm{ABC}$ classification.

(1) Class A products shall be stored in the automatic stereoscopic shelves owing to high values and strong flexibility.

(2) Class C products shall be stored in the common shelves due to weak flexibility.

(3) Class B products shall be jointly stored in the automatic stereoscopic shelves with Class A products.

TABLE I: RESULTS OF ABC CLASSIFICATION

\begin{tabular}{|c|c|c|c|c|c|c|c|c|}
\hline $\begin{array}{c}\text { Beverage } \\
\text { name }\end{array}$ & $\begin{array}{l}\text { No. of } \\
\text { items } \\
\text { (1) }\end{array}$ & $\begin{array}{c}\text { Accumulated } \\
\text { item percentage } \\
(2)\end{array}$ & $\begin{array}{l}\text { Unit } \\
\text { price } \\
(3)\end{array}$ & $\begin{array}{l}\text { Daily mean } \\
\text { sales } \\
\text { volumes (4) }\end{array}$ & $\begin{array}{c}\text { Daily mean sales } \\
\text { amount } \\
(5)=(3) \times(4) \\
\end{array}$ & $\begin{array}{c}\text { Daily } \\
\text { accumulated sales } \\
\text { amount }(6) \\
\end{array}$ & $\begin{array}{c}\text { Accumulated } \\
\text { percentage of capital } \\
\text { occupation }(7)\end{array}$ & Classification \\
\hline D1 & 1 & $1.85 \%$ & 3 & 3140 & 9420 & 9420.00 & $23.18 \%$ & \multirow{11}{*}{ A-class } \\
\hline D2 & 2 & $3.70 \%$ & 5 & 1510 & 7550 & 16970.00 & $41.75 \%$ & \\
\hline D3 & 3 & $5.56 \%$ & 4 & 902 & 3608 & 20578.00 & $50.63 \%$ & \\
\hline D4 & 4 & $7.41 \%$ & 2.5 & 906 & 2265 & 22843.00 & $56.20 \%$ & \\
\hline D5 & 5 & $9.26 \%$ & 2.5 & 800 & 2000 & 24843.00 & $61.12 \%$ & \\
\hline D6 & 6 & $11.11 \%$ & 3.5 & 478 & 1673 & 26516.00 & $65.24 \%$ & \\
\hline D7 & 7 & $12.96 \%$ & 3 & 464 & 1392 & 27908.00 & $68.67 \%$ & \\
\hline D8 & 8 & $14.81 \%$ & 3 & 400 & 1200 & 29108.00 & $71.62 \%$ & \\
\hline D9 & 9 & $16.67 \%$ & 3.5 & 140 & 490 & 29598.00 & $72.82 \%$ & \\
\hline D10 & 10 & $18.52 \%$ & 4.5 & 102 & 459 & 30057.00 & $73.95 \%$ & \\
\hline D11 & 11 & $20.37 \%$ & 2.5 & 174 & 435 & 30492.00 & $75.02 \%$ & \\
\hline D12 & 12 & $22.22 \%$ & 3 & 144 & 432 & 30924.00 & $76.09 \%$ & \multirow{16}{*}{ B-class } \\
\hline D13 & 13 & $24.07 \%$ & 5 & 84 & 420 & 31344.00 & $77.12 \%$ & \\
\hline D14 & 14 & $25.93 \%$ & 2 & 208 & 416 & 31760.00 & $78.14 \%$ & \\
\hline D15 & 15 & $27.78 \%$ & 4 & 100 & 400 & 32160.00 & $79.13 \%$ & \\
\hline D16 & 16 & $29.63 \%$ & 3.5 & 112 & 392 & 32552.00 & $80.09 \%$ & \\
\hline D17 & 17 & $31.48 \%$ & 4 & 96 & 384 & 32936.00 & $81.04 \%$ & \\
\hline D18 & 18 & $33.33 \%$ & 3 & 128 & 384 & 33320.00 & $81.98 \%$ & \\
\hline D19 & 19 & $35.19 \%$ & 4.5 & 84 & 378 & 33698.00 & $82.91 \%$ & \\
\hline D20 & 20 & $37.04 \%$ & 2.5 & 150 & 375 & 34073.00 & $83.83 \%$ & \\
\hline D21 & 21 & $38.89 \%$ & 4 & 93 & 372 & 34445.00 & $84.75 \%$ & \\
\hline D22 & 22 & $40.74 \%$ & 2 & 184 & 368 & 34813.00 & $85.66 \%$ & \\
\hline D23 & 23 & $42.59 \%$ & 3 & 120 & 360 & 35173.00 & $86.54 \%$ & \\
\hline D24 & 24 & $44.44 \%$ & 4 & 90 & 360 & 35533.00 & $87.43 \%$ & \\
\hline D25 & 25 & $46.30 \%$ & 3 & 120 & 360 & 35893.00 & $88.31 \%$ & \\
\hline D26 & 26 & $48.15 \%$ & 3.5 & 102 & 357 & 36250.00 & $89.19 \%$ & \\
\hline D27 & 27 & $50.00 \%$ & 4 & 88 & 352 & 36602.00 & $90.06 \%$ & \\
\hline D28 & 28 & $51.85 \%$ & 2 & 174 & 348 & 36950.00 & $90.91 \%$ & \multirow{27}{*}{ C-class } \\
\hline D29 & 29 & $53.70 \%$ & 5 & 65 & 325 & 37275.00 & $91.71 \%$ & \\
\hline D30 & 30 & $55.56 \%$ & 6.5 & 44 & 286 & 37561.00 & $92.42 \%$ & \\
\hline D31 & 31 & $57.41 \%$ & 2.5 & 112 & 280 & 37841.00 & $93.11 \%$ & \\
\hline D32 & 32 & $59.26 \%$ & 3 & 88 & 264 & 38105.00 & $93.76 \%$ & \\
\hline D33 & 33 & $61.11 \%$ & 2.5 & 104 & 260 & 38365.00 & $94.40 \%$ & \\
\hline D34 & 34 & $62.96 \%$ & 2.5 & 104 & 260 & 38625.00 & $95.03 \%$ & \\
\hline D35 & 35 & $64.81 \%$ & 2.5 & 96 & 240 & 38865.00 & $95.63 \%$ & \\
\hline D36 & 36 & $66.67 \%$ & 5 & 44 & 220 & 39085.00 & $96.17 \%$ & \\
\hline D37 & 37 & $68.52 \%$ & 1.5 & 126 & 189 & 39274.00 & $96.63 \%$ & \\
\hline D38 & 38 & $70.37 \%$ & 6.5 & 27 & 175.5 & 39449.50 & $97.06 \%$ & \\
\hline D39 & 39 & $72.22 \%$ & 5 & 31 & 155 & 39604.50 & $97.44 \%$ & \\
\hline D40 & 40 & $74.07 \%$ & 4 & 30 & 120 & 39724.50 & $97.74 \%$ & \\
\hline D41 & 41 & $75.93 \%$ & 3 & 30 & 90 & 39814.50 & $97.96 \%$ & \\
\hline D42 & 42 & $77.78 \%$ & 2 & 43 & 86 & 39900.50 & $98.17 \%$ & \\
\hline D43 & 43 & $79.63 \%$ & 2.5 & 34 & 85 & 39985.50 & $98.38 \%$ & \\
\hline D44 & 44 & $81.48 \%$ & 5 & 16 & 80 & 40065.50 & $98.58 \%$ & \\
\hline D45 & 45 & $83.33 \%$ & 2.5 & 28 & 70 & 40135.50 & $98.75 \%$ & \\
\hline D46 & 46 & $85.19 \%$ & 3 & 23 & 69 & 40204.50 & $98.92 \%$ & \\
\hline D47 & 47 & $87.04 \%$ & 2 & 34 & 68 & 40272.50 & $99.09 \%$ & \\
\hline D48 & 48 & $88.89 \%$ & 2.5 & 25 & 62.5 & 40335.00 & $99.24 \%$ & \\
\hline D49 & 49 & $90.74 \%$ & 3.5 & 17 & 59.5 & 40394.50 & $99.39 \%$ & \\
\hline D50 & 50 & $92.59 \%$ & 6.5 & 9 & 58.5 & 40453.00 & $99.53 \%$ & \\
\hline D51 & 51 & $94.44 \%$ & 2.5 & 23 & 57.5 & 40510.50 & $99.67 \%$ & \\
\hline D52 & 52 & $96.30 \%$ & 5 & 10 & 50 & 40560.50 & $99.80 \%$ & \\
\hline D53 & 53 & $98.15 \%$ & 3.5 & 12 & 42 & 40602.50 & $99.90 \%$ & \\
\hline D54 & 54 & $100.00 \%$ & 1.5 & 27 & 40.5 & 40643.00 & $100.00 \%$ & \\
\hline
\end{tabular}




\section{2) Sorting Strategy Design Based On EIQ Analysis Method}

Sorting efficiency can directly influence the performance of the customer orders in the logistics distribution center. Therefore, EIQ analysis is applied to analyze the warehouseout materials in the orders, determine the features of customers' orders, and create an effective sorting strategy to improve order sorting efficiency and customer satisfaction.

a) Sorting strategy

1. Sorting strategy for division: Areas are divided in accordance with the site for sorting operation. Four division methods are as follows: division according to goods characteristics, sorting units (e.g., box and item divisions), sorting methods (e.g., mass and order sorting), and work [10].

2. Order splitting strategy: Orders are divided into several sub-orders according to the sorting area when the orders have numerous items to enable quick and timely response to such orders.

3. Order batching strategy: Many orders are combined as one batch for sorting to increase sorting efficiency [11].

i. Total batching strategy: The goods and items are accumulated in all the orders before sorting and are then sorted in accordance with the accumulated volume of each item. Finally, they are classified in accordance with each order.

ii. Batching with time window: The orders are batched according to a certain period upon receiving the orders.

iii. Fixed number batching: The orders are batched according to the fixed number in the order following the order receipt time.

iv. Intelligent batching: Orders with similar sorting paths are handled simultaneously through computer processing.

\section{b) Order Analysis}

The EIQ analysis method (analysis method on entry, item, and quantity of the order) is adopted to plan for the system in the distribution center [12], [13]. EIQ has the following representations: $\mathrm{E}$ (entry) refers to the distribution target or customer, I (item) refers to the type of distributed goods, and $\mathrm{Q}$ (quantity) refers to the distributed quantity. EIQ analysis primarily investigates the warehouse-out features from the perspective of the items, quantities, and ordered numbers in the customers' orders. On the basis of document samples of the warehouse-out orders, statistical analysis of the entry quantity (EQ), entry number of order items (EN), item quantity (IQ), and items by order number (IK) is conducted via frequency distribution diagrams, and $\mathrm{ABC}$ analysis instruments to acquire the planning information.

$\mathrm{X}$ Beverage Company provides a large amount of commodity data with a stable overall ordering quantity for large and small retailers. Hence, this study conducts EIQ statistics analysis to the ordering information of small retailers for only one day in $\mathrm{Y}$ region.

\section{(1) EQ Analysis}

EQ analysis evaluates the order quantity of the customers and arranges the order quantity from the maximum to the minimum. Then, key management is created to the customer orders through ABC analysis. Fig. 3 indicates that EQ is of polarized distribution; therefore, $\mathrm{ABC}$ classification can be conducted because of the large vibrations of EQ (Table II).

Analysis results in Table II confirm that Class A orders are the biggest orders, whose orders and its quantity for $21.95 \%$ and $43.72 \%$ of the total volume, respectively. Order splitting can be considered to implement sorting by division. Class B orders are the bigger orders, whose orders and its quantity for $34.15 \%$ and $37.86 \%$ of the total volume, respectively. General sorting and sorting together with part of Class A orders can be considered. Class C orders are the most demanding orders because despite the limited total quantity (accounting for $18.42 \%$ of the total volume), the orders are numerous (accounting for $43.90 \%$ of the total volume). A sorting method of combined orders can be implemented to increase operation efficiency.

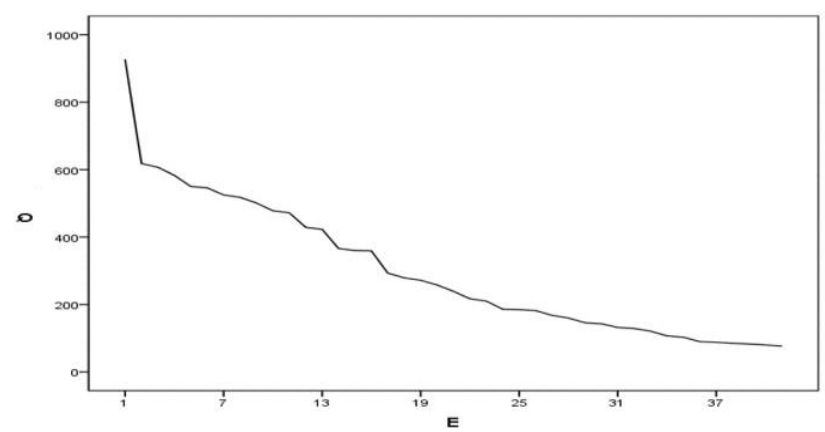

Fig. 3. Frequency distribution diagram of EQ analysis

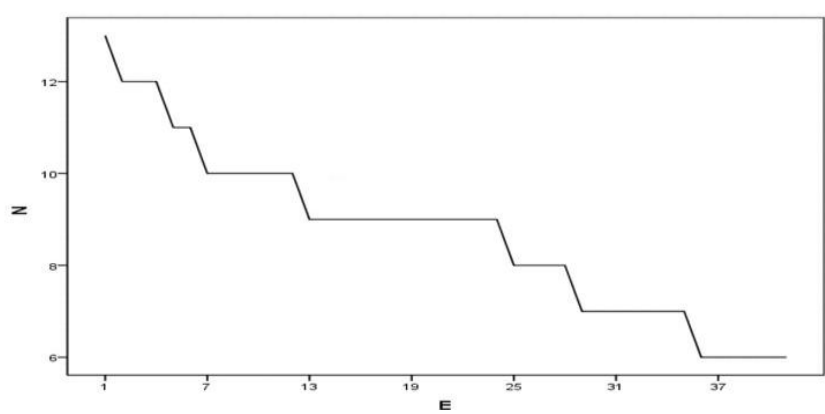

Fig. 4. Frequency distribution diagram of EN analysis

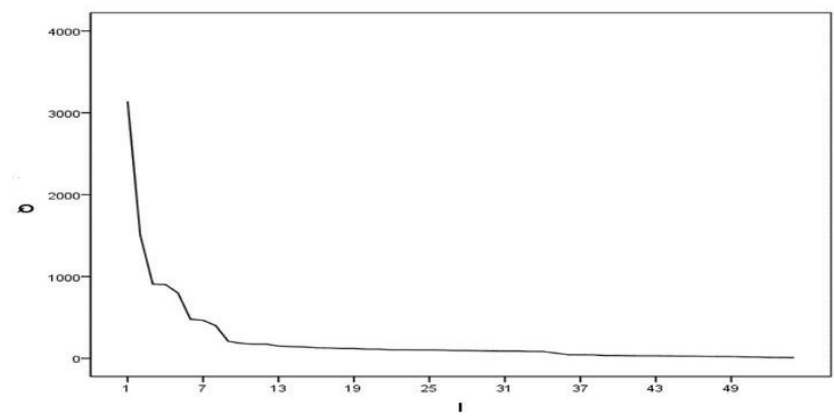

Fig. 5. Frequency distribution diagram of IQ analysis 
TABLE II: RESULTS OF EQ ANALYSIS

\begin{tabular}{|c|c|c|c|c|c|c|}
\hline Classification & Number of order items & Number of orders & $\begin{array}{l}\text { Proportion of } \\
\text { orders }\end{array}$ & Order quantity & $\begin{array}{c}\text { Proportion of order } \\
\text { quantity }\end{array}$ & $\begin{array}{c}\text { Average order } \\
\text { quantity }\end{array}$ \\
\hline \multirow{6}{*}{ A-class } & $900-1000$ & 1 & $2.44 \%$ & 927 & $7.54 \%$ & 927 \\
\hline & $800-899$ & 0 & 0 & 0 & 0 & 0 \\
\hline & $700-799$ & 0 & 0 & 0 & 0 & 0 \\
\hline & $600-699$ & 2 & $4.88 \%$ & 1225 & $9.96 \%$ & 612.5 \\
\hline & $500-599$ & 6 & $14.63 \%$ & 3223 & $26.21 \%$ & 537.17 \\
\hline & Total & 9 & $21.95 \%$ & 5375 & $43.72 \%$ & 597.22 \\
\hline \multirow{4}{*}{ B-class } & $400-499$ & 4 & $9.76 \%$ & 1802 & $14.66 \%$ & 450.5 \\
\hline & $300-399$ & 3 & $7.32 \%$ & 1805 & $8.82 \%$ & 361.67 \\
\hline & $200-299$ & 7 & $17.07 \%$ & 1768 & $14.38 \%$ & 252.57 \\
\hline & Total & 14 & $34.15 \%$ & 4655 & $37.86 \%$ & 332.5 \\
\hline \multirow{3}{*}{ C-class } & $100-199$ & 12 & $29.27 \%$ & 1762 & $14.33 \%$ & 146.83 \\
\hline & $0-99$ & 6 & $14.63 \%$ & 503 & $4.09 \%$ & 83.83 \\
\hline & Total & 18 & $43.90 \%$ & 2265 & $18.42 \%$ & 125.83 \\
\hline \multicolumn{7}{|c|}{ TABLE III: RESULTS OF EN ANALYSIS } \\
\hline Classification & Number of order items & $\begin{array}{l}\text { Total order } \\
\text { quantity }\end{array}$ & $\begin{array}{c}\text { Proportion of order } \\
\text { quantity }\end{array}$ & Number of orders & $\begin{array}{l}\text { Proportion of } \\
\text { orders }\end{array}$ & $\begin{array}{c}\text { Average order } \\
\text { quantity }\end{array}$ \\
\hline A-class & $\begin{array}{c}\text { Greater than or equal to } \\
10\end{array}$ & 3722 & $2.44 \%$ & 12 & $29.27 \%$ & 310.17 \\
\hline B-class & 9 & 4062 & $33.04 \%$ & 12 & $29.27 \%$ & 338.5 \\
\hline C-class & Less than or equal to 8 & 4511 & $36.69 \%$ & 17 & $41.46 \%$ & 265.35 \\
\hline
\end{tabular}

TABLE IV: RESULTS OF IQ ANALYSIS

\begin{tabular}{|c|c|c|c|c|c|}
\hline Classification & $\begin{array}{c}\text { Range of order } \\
\text { quantity }\end{array}$ & Number of items & Proportion of items & Order quantity & $\begin{array}{c}\text { Proportion of order } \\
\text { quantity }\end{array}$ \\
\hline A-class & $\begin{array}{l}\text { Greater than or equal } \\
\text { to } 400\end{array}$ & 8 & $14.82 \%$ & 8600 & $69.95 \%$ \\
\hline B-class & $100-399$ & 18 & $33.33 \%$ & 2404 & $19.55 \%$ \\
\hline C-class & $0-99$ & 28 & $51.85 \%$ & 1291 & $10.50 \%$ \\
\hline \multicolumn{6}{|c|}{ TABLE V: RESULTS OF IK ANALYSIS } \\
\hline Classification & Order frequency of items & Number of items & Proportion of items & Order quantity & $\begin{array}{c}\text { Proportion of order } \\
\text { quantity }\end{array}$ \\
\hline A-class & Greater than or equal to 9 & 4 & $7.40 \%$ & 441 & $3.59 \%$ \\
\hline B-class & 8 & 14 & $25.93 \%$ & 5854 & $47.61 \%$ \\
\hline C-class & Less than or equal to 7 & 36 & $66.67 \%$ & 6000 & $48.8 \%$ \\
\hline
\end{tabular}

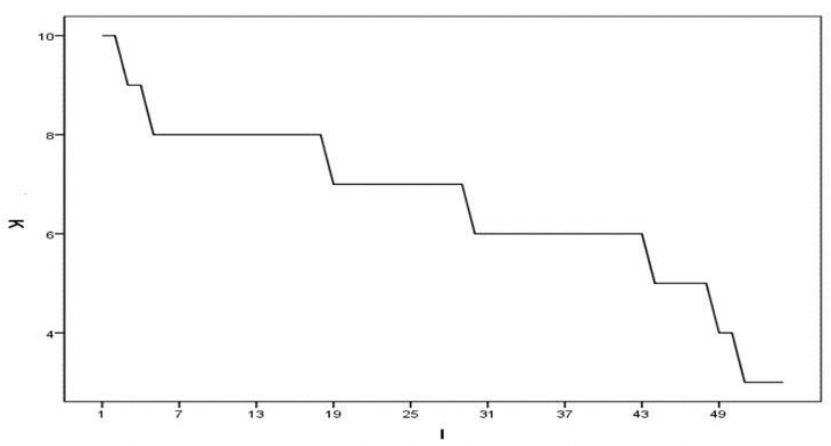

Fig. 6. Frequency distribution diagram of IK analysis

\section{(2) EN Analysis}

$\mathrm{EN}$ analysis is applied specifically to the items in each order to analyze the sorting time and human resource demands after the ordered items are accumulated. Overall, 54 warehouse-out items are present; the maximum is 13 and the minimum is 6 in a single order. Imbalance will occur between the numerous sorting equipment and sorting workload if all the orders are operated in one sorting equipment. Therefore, order sorting is implemented to divide the orders into different zones, time periods, or sorting equipment. Fig. 4 indicates that the EN is of polarized distribution. Thus, ABC classification can be conducted because of the large vibrations of order frequency (Table III).
Table III suggests that Class A orders have multiple items, for which order splitting shall be applied for sorting. In comparison with Class A orders, Class B orders generally have more items, for which general sorting shall be adopted. Class $\mathrm{C}$ orders have only a few items but with numerous orders, which account for $41.46 \%$ of the total orders. Thus, apart from the general sorting method, combined sorting is advised for orders with comparatively small order frequencies.

\section{(3) IQ Analysis}

IQ analysis evaluates the shipment quantity of product items, which shall be arranged from the maximum to the minimum. Best sellers shall be indicated, and products shall be classified according to ABC. The plot of IQ distribution (Fig. 5) can indicate that a distribution center is common because the quantity of shipping items is of polarized distribution, thereby possibly allowing for the management of the items through ABC (Table IV).

The analysis results in Table IV confirm that only eight items have order quantity over 400 , accounting for $14.82 \%$ of the total items; whereas the order quantity have reached 8,600 , which account for $69.95 \%$ of the total order quantity. The eight items can be classified as Class A products, which shall be of key management and positioned sideways and as close to the doors as possible in 
the plan. Moreover, they shall be placed on the first layer of the exhibition shelf for easy fetching.

\section{(4) IK Analysis}

IK analysis studies the order frequency of the product items to understand the demanded shipping quantity of each product for every time. The positions of the product items in the distribution center are studied after the order frequency of each product item is accumulated. Fig. 6 indicates that the order frequency is of polarized distribution. Thus, ABC classification can be conducted because of the substantial vibrations of order frequency (Table V).

Table V shows that Class A orders have multiple items and few orders, for which combined order strategy shall be applied. In comparison with Class A orders, Class B orders generally have less items and more orders, accounting for $47.61 \%$ of the total order quantity. Apart from the general sorting method, order splitting strategy shall be adopted for such orders. Class $\mathrm{C}$ orders have only a few items but numerous orders, for which order splitting shall be considered.

In conclusion, based on the analysis of EQ, EN, IQ and IK, it can be a common distribution center because the order quantity and items are of polarized distribution. Therefore, the implementation of combined sorting strategies is advised.

\section{3) Stock Control}

Classified as fast-moving consumer goods (FMCG), beverages depend on the repetitive reuse and consumption of customers and gain profits from massive market quantities, thereby featuring large changes in sales quantity and considerable flexibility on demands. Therefore, stock control of beverage shall be rationally controlled under the safety stock level to ensure normal supply for orders without overstock. The model of economic order quantity (EOQ) is adopted to determine the appropriate ordering level and safety stock level to minimize the cost of stock because all retailers in Y region have stable orders [14], [15].

\section{a) Optimal Economic Order Quantity}

This study uses hot peach juice as an example. In large and small retailers in $\mathrm{Y}$ region, the total distribution quantity of peach juice is 2,400 boxes every day, among which 240 boxes go to the small retailers and 2,160 boxes go to the large retailers. The price of peach juice is 2.5 yuan/bottle, and 40 bottles comprise a box. For the large retailers, the average ordering cost of the warehouse is nearly 150 yuan and storage cost comprises nearly $15 \%$ of the goods value. For the small retailers, the ordering cost is nearly 50 yuan and storage cost comprises $20 \%$ of the goods value.

With the assumption that a year has 365 days, Equation (1) and (2) present the total inventory cost of the large and small retailers, respectively. In (1) and (2), the total demanded quantities of the large and small retailers for the whole year are $D_{\text {large }}$ retailers $=2160 \times 365$ and $D_{\text {small }}$ retailers $=240 \times 365$, respectively. The cost savings of the large and small retailers are $S_{\text {large retailers }}=150$ and $S_{\text {small retailers }}=50$, respectively. The ordering costs of the large and small retailers are $H_{\text {large }}$ retailers $=2.5 \times 40 \times 0.15$ and $H_{\text {small }}$ retailers $=2.5 \times 40 \times 0.20$, respectively. Equation (3) and (4) present the optimal EOQ of the large and small retailers, respectively.

$$
\begin{aligned}
& T C_{\text {large retailers }} \\
& =\frac{D_{\text {large retailers }}}{Q_{\text {large retailers }}} \times S_{\text {large retailers }}+\frac{Q_{\text {large retailers }}}{2} \times H_{\text {large retailers }} \\
& =\frac{2160 \times 365}{Q_{\text {large retailers }}} \times 150+\frac{Q_{\text {large retailers }}}{2} \times(2.5 \times 40 \times 0.15) \\
& T C_{\text {small retailers }} \\
& =\frac{D_{\text {small retailers }}}{Q_{\text {small retailers }}} \times S_{\text {small retailers }}+\frac{Q_{\text {small retailers }}}{2} \times H_{\text {small retailers }} \\
& =\frac{240 \times 365}{Q_{\text {small retailers }}} \times 50+\frac{Q_{\text {small retailers }}}{2} \times(2.5 \times 40 \times 0.20) \\
& Q_{\text {large retailers }}^{*}=\sqrt{\frac{2 \times D_{\text {large retailers }} \times S_{\text {large retailers }}}{H_{\text {large retailers }}}} \\
& =\sqrt{\frac{2 \times 2160 \times 365 \times 150}{2.5 \times 40 \times 0.15}}=3970.89 \approx 3971 \\
& Q_{\text {small retailers }}^{*}=\sqrt{\frac{2 \times D_{\text {small retailers }} \times S_{\text {small retailers }}}{H_{\text {small retailers }}}} \\
& =661.82 \approx 662
\end{aligned}
$$

Equation (5) and (6) present the total ordering frequencies of the large and small retailers, respectively. Equation (7) and (8) present the optimal inventory costs of the large and small retailers, respectively.

$$
\begin{aligned}
& F_{\text {large retailers }}^{*}=\frac{D_{\text {large retailers }}}{Q_{\text {large retailers }}^{*}}=\frac{2160 \times 365}{3971}=198.54 \approx 199 \\
& F_{\text {small retailers }}^{*}=\frac{D_{\text {small retailers }}}{Q_{\text {small retailers }}^{*}}=\frac{240 \times 365}{662}=132.33 \approx 133 \\
& T C_{\text {large retailers }}^{*}=\frac{2160 \times 365}{3971} \times 150+\frac{3971}{2} \times(2.5 \times 40 \times 0.15)=59563.41 \\
& T C_{\text {small retailers }}^{*}=\frac{240 \times 365}{662} \times 50+\frac{662}{2} \times(2.5 \times 40 \times 0.20)=13236.31
\end{aligned}
$$

Large retailers can be deduced to have the optimal inventory costs at 59, 563.41 yuan when optimal EOQ is 3,971 boxes every time, with annual ordering frequencies of 199 orders. Small retailers have the optimal inventory cost of 13, 236.31 yuan when optimal EOQ is 662 boxes every time, with annual ordering frequencies of 133 orders.

\section{b) Safety Stock}

Small retailers are unstable compared with large retailers because of the different products and quantities in their orders. Thus, safety stock shall be made for orders from the small retailers to meet the demands of lead time to prevent uncertainties, such as urgent large orders, abrupt early delivery, temporary usage addition, delivery failure, and other special reasons.

The data indicate that implementation of small retailers' orders shall be strictly within 24 hours. Therefore, the lead 
time is one day ( 24 hours). Considering the numerous kinds of commodity, this study focuses only on the hot peach juice, which has a total daily distribution of 2,40 boxes for all the small retailers. However, only a few small retailers have eight orders for peach juice at the total daily volume of 800 bottles after handling all the statistics. The distribution load of one day is therefore 20 boxes because 40 bottles form one box (Table VI).

Table VI infers on the ordering information of a few small retailers in one day. Daily orders are eight, of which the average of order quantity is $800 \div 8=100$ bottles; the maximum of order quantity is 240 bottles, and the minimum of order quantity is 24 bottles. Daily orders from all the small retailers in $\mathrm{Y}$ region is $8 \times 12=96$ according to the proportion. Suppose $x_{1}, x_{2}, \ldots, x_{96}$ indicates the daily order quantity of the 96 orders, and such order quantity is between 24 240 bottles. Presumably, $24 \leq x_{1}, x_{2}, \ldots, x_{96} \leq 240$ daily mean order quantity of small retailers in $\mathrm{Y}$ region is $\bar{x}=\sum_{i=1}^{96} x_{i} / 96=100$ (pieces), $\max \left\{x_{1}, x_{2}, \ldots, x_{96}\right\}=240$ and $\min \left\{x_{1}, x_{2}, \ldots, x_{96}\right\}=24$. Therefore, the range is $\mathrm{R}=$ $240-24=216$.

The range is nearly six times the standard deviation. Therefore, the standard deviation of daily order quantity from the small retailers in $\mathrm{Y}$ region is inferred to be $s_{x}=$ $R / 6=216 / 6=36$ (pieces). The standard error of mean of daily order quantity from the small retailers in $\mathrm{Y}$ region is thus $s_{\bar{x}}=s_{x} / \sqrt{96}=36 / \sqrt{96}=3.67$ (pieces).

As the lead time (LT) is 1 day, the daily demand for peach juice of the small retailers in Y region within LT $=1$ day is $d_{1}=96 \bar{x}=96 \times 100=9,600$ (pieces), and the standard deviation of the daily demand $d_{1}$ is $s_{d_{1}}=96 s_{\bar{x}}=$ 352.73 (pieces). Suppose the service level is $99 \%$. Then, the safety stock of the peach juice in the small retailers in $\mathrm{Y}$ within LT=1 day is $\mathrm{SS}=z_{1-\alpha} s_{d_{1}}=z_{99 \%} s_{d_{1}}=2.33 \times$ $352.73=821.86 \cong 822$ (pieces).

Therefore, the daily demand for peach juice of the small retailers in Y region is 240 (boxes) $=9,600$ (pieces), and safety stock is $S S=822$ (pieces). Reorder point (ROP) is 9,600 (pieces) +822 (pieces) $=10,422$ (pieces)

According to EOQ results, small retailers must send the purchase demands when the stock of peach juice is reduced to 10,422 bottles when the EOQ is 622 boxes (Fig. 7).

TABLE VI. ORDER INFORMATION OF FEW SMALL RETAILER SHOPS

\begin{tabular}{cc}
\hline \hline Order & Order amount \\
\hline Order 1 Pieces ) \\
\hline Order 2 & 240 \\
Order 3 & 24 \\
Order 4 & 24 \\
Order 5 & 40 \\
Order 6 & 160 \\
Order 7 & 40 \\
Order 8 & 32 \\
Total & 240 \\
\hline \hline
\end{tabular}

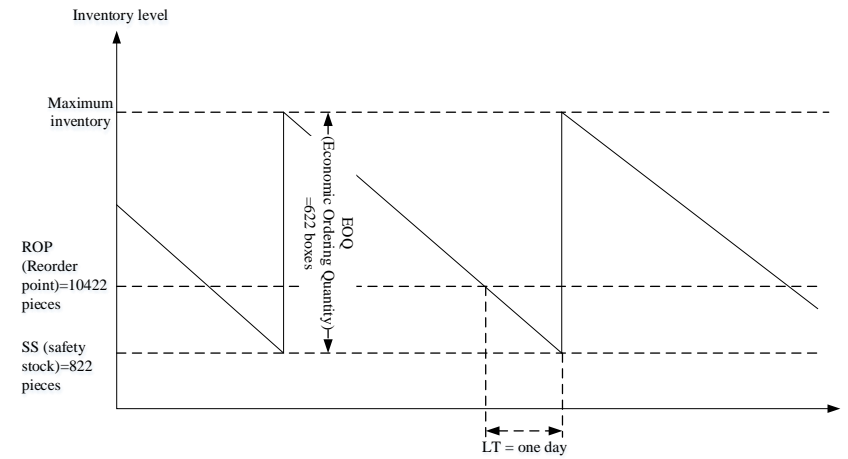

Fig. 7. Inventory change under EOQ model of small retailer shops in Y region

\section{CONCLUSION}

Storage and maintenance are essential in the three processes (warehouse-in, warehouse-out, and storage and maintenance) of warehouse operation management. Thus, this study uses a logistics distribution center as a case. In this case, reducing goods overstock, stock, and stock-out rate and improving the goods' freshness are concerns of $\mathrm{X}$ Beverage Company because its products, which are beverages, are FMCG. In this case, Logistics Company A and $\mathrm{X}$ Beverage Company establish a logistics partnership in the supply chain. Logistics Company A designs and handles X Beverage Company's cargo storage, transportation, and distribution businesses in the big and small retail shops in $\mathrm{Y}$ region. This study initially adopts classified management of goods by $\mathrm{ABC}$ to achieve a scientific and rational formulation of the storage strategy of goods from X Beverage Company in logistics distribution of Logistics Company A and thus increase the efficiency of storage management. Second, goods stock and management strategies are developed in accordance with the results of the ABC classification. Finally, a stock control model is established for the large and small retailers.

According to the results of the data analysis, beverages in $\mathrm{X}$ Beverage Company have 11 drinks with the highest stock value (Class A), whose daily sales amount accounts for $75.02 \%$ of the total amount on average. Second, 16 drinks have lower stock values than those in Class A (Class B), whose daily sales amount is accumulated to account for $15.04 \%$ of the total amount on average. Finally, 27 drinks have the lowest stock values (Class C), whose daily sales amount accounts for $9.94 \%$ of the total amount on average. Therefore, Class A and B products with high values shall be stored in the automatic stereoscopic shelves because of their strong flexibility. Class $\mathrm{C}$ products, which have low values, shall be stored in the common pallet shelves due to their weak flexibility.

Finally, the EOQ model is adopted for the stock management of beverages to determine the appropriate ordering level and safety stock and minimize stock cost. According to the analysis results, the large retailers have the optimal stock costs at 59,563.41 yuan when optimal EOQ is 3,971 boxes every time, with annual ordering frequencies of 199 orders. Small retailers must send their purchase demands when the stock of peach juice is reduced to 10,422 bottles when the EOQ is 622 boxes. 


\section{REFERENCES}

[1] X. M. Zhu, "Strengthening the management of college storehouse to improve economic benefit," Laboratory Research \& Exploration, vol. 21, no. 2, pp. 134-134, 2002.

[2] S. K. Srivastava, "Improving the warehouse management in the Indian scenario," 13th Annual International Conference of the Society of Operations Management, Indian Institute of Technology Madras, 2009.

[3] K. S. Tan, M. D. Ahmed and D. Sundaram, "Sustainable warehouse management," Proceedings of the International Workshop on Enterprises \& Organizational Modeling and Simulation, pp. 1-15, 2009.

[4] J. X. Gu, M. Goetschalckx and L. F. McGinnis, "Research on warehouse operation: A comprehensive review," European Journal of Operational Research, vol. 177, no. 1, pp. 1-21, 2007.

[5] Q. F. Yu, "Design and realization of warehouse management system," M.S. thesis, Dept. Software engineering, University of Electronic Science and technology, 2013.

[6] Y. Min, "The research and development of supply distribution store system based on B/S structure in Garments," M.S. thesis, Dept. Software Engineering, Jilin University, Jilin, China, 2014.

[7] B. M. Huang, "Warehousing management in distribution center of DHL for NOKIA," M.S. thesis, Dept. Business Administration, Beijing Jiaotong University, Beijing, China, 2010.

[8] R. H. Teunter, M. Z. Babai and A. A. Syntetos, "ABC Classification: Service levels and inventory costs," Production \& Operations Management, vol. 19, no. 3, pp. 343-352, 2010.

[9] R. Chai and F. X. Huang, "Application of ABC classification method in the inventory management of interventional supplies," China Modern Medicine, vol. 22, no. 24, pp. 138-140, 2015.

[10] G. C. Wei, Modern Logistics Technology and Practice, Beijing: China Material Press, 2007.

[11] S. Z. Li, Z. Wang and K. C. Zhang, "Study on order batching strategy in picking system of a distribution center," Logistics Technology, vol. 4, pp. 31-33, 2002.

[12] W. Yang and J. J. Cao, "The use of EIQ method on designing picking system of distribution center," Machinery Design \& Manufacture, vol. 9, pp. 160-161, 2006

[13] S. Zhong and D.H. Zhu, "The Application of EIQ-ABC analysis method in the storage management of GX Company," Logistics Engineering \& Management, vol. 110, no. 23, pp. 9517-9522, 2014.

[14] E. L. Porteus, "Investing in reduced setups in the EOQ model," Management Science, vol. 31, no. 8, pp. 998-1010, 1985.

[15] K. J. Chung, P. Chub and S. P. Lanc, "A note on EOQ models for deteriorating items under stock dependent selling rate," European Journal of Operational Research, vol. 124, no. 3, pp. 550-559, 2000.

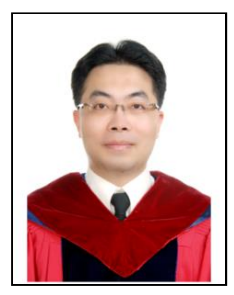

Ching-Kuei Kao is Assistant Professor of the Department of Logistics Management, Beijing Institute of Technology, Zhuhai. He received his PhD degree in industrial engineering and management from National Chiao-Tung University in Taiwan. His research interests include production planning and scheduling, supply chain management and decision, and application of statistical analysis in logistics and engineering.
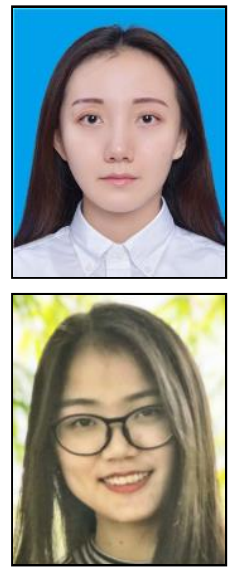

Guo-Xia Xu at present is a student in Department of logistics management at Beijing Institute of Technology, Zhuhai. Her areas of interest are supply chain management, logistics cost control, and inventory management.

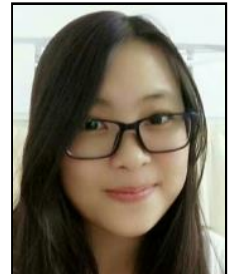

Mei-Chun Zheng at present is a college student in Department of logistics management at Beijing Institute of Technology, Zhuhai. Her areas of interest are transportation planning and supply chain management. 